\title{
Vacuolar myopathy in a dog resembling human sporadic inclusion body myositis
}

\author{
Jason King • Richard A. LeCouteur • Monica Aleman • \\ D. Colette Williams $\cdot$ Peter F. Moore $\cdot$ Ling T. Guo • \\ Andrew P. Mizisin · G. Diane Shelton
}

Received: 11 July 2009/Revised: 18 August 2009/ Accepted: 19 August 2009/Published online: 29 August 2009

(C) The Author(s) 2009. This article is published with open access at Springerlink.com

\begin{abstract}
Sporadic inclusion body myositis (sIBM) is the most common myopathy in people over the age of 50 years. While immune-mediated inflammatory myopathies are well documented in dogs, sIBM has not been described. An 11-year-old dog with chronic and progressive neuromuscular dysfunction was evaluated for evidence of sIBM using current pathologic, immunohistochemical and electron microscopic diagnostic criteria. Vacuoles and congophilic intracellular inclusions were identified in cryostat sections of multiple muscle biopsies and immunostained with antibodies against amyloid- $\beta$ peptide, amyloid- $\beta$ precursor protein, and proteosome $20 \mathrm{~S}$ of the ubiquitin-proteosome system. Cellular infiltration and increased expression of MHC Class I antigen were observed. Cytoplasmic filamentous inclusions, membranous structures, and myeloid bodies were identified ultrastructurally. These observations constitute the first evidence that both the inflammatory and degenerative features of human sIBM can occur in a non-human species.
\end{abstract}

Keywords Canine $\cdot$ Muscle $\cdot$ Myopathy $\cdot$ Inflammatory Aging

J. King · R. A. LeCouteur · M. Aleman · D. C. Williams Veterinary Medical Teaching Hospital, School of Veterinary Medicine, University of California, Davis, Davis, CA, USA

\section{P. F. Moore}

Department of Pathology, Microbiology, and Immunology, School of Veterinary Medicine, University of California, Davis, Davis, CA, USA

L. T. Guo · A. P. Mizisin · G. D. Shelton ( $\varangle)$ Department of Pathology, School of Medicine, University of California San Diego,

La Jolla, CA 92093-0709, USA

e-mail: gshelton@ucsd.edu

\section{Introduction}

The inflammatory myopathies (IMs) are a heterogeneous group of diseases characterized by muscle degeneration mediated by inflammatory and immune-mediated processes. The most common IMs of humans are polymyositis (PM), dermatomyositis (DM), and sporadic inclusion body myositis (sIBM) [13, 16]. Other less common IMs of humans include focal myositis, infectious myositis, macrophagic myositis [11], and IM with abundant macrophages [7]. There are many similarities between human and spontaneous canine IMs, including a broad spectrum of underlying causes [41]. In dogs, the most frequently reported IMs include the highly specific immune-mediated masticatory muscle myositis [37, 42], polymyositis that resembles PM of humans [18, 27, 41], and generalized myositis from infectious causes [8, 14, 21, 31, 38]. Extraocular myositis is a less commonly occurring focal immune-mediated IM [1,9]. Dermatomyositis, occurs in certain breeds of dogs [23-25] and similar to human DM, is associated with characteristic skin, muscle, and vascular lesions. Although not yet fully characterized, IMs with predominantly histiocytic cellular infiltration and similarities to macrophagic myofascitis, and IM with abundant macrophages have been identified in dogs (Shelton 2009, unpublished observation).

Sporadic inclusion body myositis is the most common progressive, degenerative and inflammatory myopathy in humans over the age of 50 years [17, 34], and the most debilitating muscle disease associated with aging [3, 4, 35]. Muscle weakness affects proximal muscles of the lower limbs and distal muscles of the thoracic limbs [17]. In contrast to patients with PM and DM, sIBM patients, as a group, respond poorly to immunosuppressive therapies suggesting that mechanisms other than an aberrant immune 
response play a key role in sIBM pathogenesis [17]. Pathologically, sIBM is characterized by the presence of bluerimmed vacuoles in muscle fibers that may have a central or subsarcolemmal location, intracellular congophilic deposits demonstrated by fluorescence microscopy of Congo-red stained muscle sections, ubiquitin positivity of the vacuoles, typical filaments shown by electron microscopy, and mononuclear cell infiltrations that may [32] or may not [10] invade non-necrotic fibers. While the exact pathogenesis of sIBM remains unknown [22, 35], interactions between aging, genetic and environmental factors are implicated. To date, sIBM remains a poorly understood disease without consistently beneficial therapies [22]. Animal homologs are widely regarded as valuable tools in the study of human disease, yet an ideal animal model that accurately reproduces both the inflammatory and degenerative components of sIBM does not exist $[22,35]$. Here we describe, for the first time, a spontaneous vacuolar myopathy in an aged dog with many similarities to human sIBM.

\section{Case description}

An 11-year-old male castrated, German shorthaired pointer was referred to the University of California, Davis, Veterinary Medical Teaching Hospital (UCD-VMTH) for evaluation of a 2-year history of chronic and progressive generalized weakness and muscle atrophy, as well as increased respiratory effort. On physical and neurological examination, generalized atrophy of the limbs, trunk and head musculature was noted. A short and choppy gait that progressed to collapse after approximately $10-20 \mathrm{~s}$ of movement was observed. Pain could not be elicited on palpation. Results of routine laboratory screening were within normal limits and serum creatine kinase (CK) activity was not elevated. A generalized neuromuscular disease was suspected.

\section{Materials and methods}

\section{Electrodiagnostic testing}

Needle electromyography (EMG) was performed under general inhalation anesthesia on numerous axial and appendicular muscles. Motor and sensory nerve conduction velocity (MNCV, SNCV) determinations were completed on the right peroneal and ulnar nerves using established techniques [36, 40, 43, 44].

\section{Light microscopy}

Biopsies from the vastus lateralis, triceps, and cranial tibial muscles were collected under general inhalation anesthesia. Specimens were flash frozen in isopentane precooled in liquid nitrogen and stored at $-80^{\circ} \mathrm{C}$ until further processed. Cryosections $(8 \mu \mathrm{m})$ were evaluated by light microscopy using a standard panel of histologic and histochemical stains and reactions [15]. Congophilic deposits were identified in Congo-red stained frozen sections with fluorescence microscopy using rhodamine optics [6] and with crystal violet staining. Unfixed cryosections were stained with monoclonal antibodies against $\beta$-amyloid precursor protein (APP, Invitrogen, Carlsbad, CA) and amyloid $\beta$ peptide (A $\beta$ 1-42, Abcam, Cambridge, MA), rabbit polyclonal antibody against proteosome 20S (Calbiochem, CA) and alpha sarcoglycan (a gift from Dr. E. Engvall, The Burnham Institute for Medical Research, La Jolla, CA, USA). Infiltrating cells were characterized in unfixed cryosections using monoclonal antibodies against canine CD4, CD8, CD11c, CD21 and MHC class II antigens (Dr. Peter Moore, University of California, Davis) and against MHC class I antigen (clone H58A, VMRD, WA). Sections were further incubated with affinity-purified fluorescein or rhodamine conjugated goat anti-mouse or anti-rabbit IgG (H\&L, Jackson ImmunoResearch Labs) prior to visualization with fluorescence microscopy.

Biopsies from the peroneal nerve also were collected under general anesthesia. One portion of the biopsy was frozen in isopentane pre-cooled in liquid nitrogen, while a second portion was immersion fixed in $2.5 \%$ glutaraldehyde in $0.1 \mathrm{M}$ phosphate buffer, rinsed, then post-fixed in $1 \%$ aqueous osmium tetroxide and embedded in araldite resin as previously described [33].

\section{Electron microscopy}

Glutaraldehyde-fixed muscle biopsy specimens were postfixed in osmium tetroxide, and were dehydrated in serial alcohol solutions and propylene oxide prior to embedding in araldite resin. Thick sections $(1 \mu \mathrm{m})$ were stained with toluidine blue for light microscopy and ultrathin sections $(60-90 \mathrm{~nm})$ were stained with uranyl acetate and lead citrate for electron microscopy.

\section{Results}

Electrodiagnostic testing

Spontaneous activity, including prolonged insertional activity, fibrillation potentials, positive sharp waves, and complex repetitive discharges, was detected in the majority of muscles examined using EMG. Spontaneous activity was mild and patchy $(1+)$ in proximal limb muscles and diffuse and moderate $(2+$ to $3+)$ distally, with the thoracic 
limb more severely affected than the pelvic limb. Motor nerve conduction velocity (MNCV) for the right sciatic/ peroneal nerve was $56-57 \mathrm{~m} / \mathrm{s}$ and for the right ulnar nerve was $49 \mathrm{~m} / \mathrm{s}$ suggestive of a mild motor neuropathy [43]. Sensory nerve conduction velocities (SNCV) for the right sciatic/peroneal $(53-60 \mathrm{~m} / \mathrm{s})$, ulnar $(55 \mathrm{~m} / \mathrm{s})$ and radial $(58 \mathrm{~m} / \mathrm{s})$ nerves were within normal limits for this geriatric dog [40]. Sensory nerve action potentials were robust for the peroneal and radial nerves, but diminutive and dispersed for the ulnar nerve. Muscle and peripheral nerve biopsies were collected from the dog's left side.

\section{Light and electron microscopy}

The proximal limb muscles (vastus lateralis and triceps) were more severely affected than the distal limb muscle (cranial tibial). In the vastus lateralis and triceps muscles, a marked variability in myofiber size was evident with hypertrophic fibers and atrophic fibers having polygonal to anguloid shapes (Fig. 1a), of both fiber types and with a type 1 fiber predominance (not shown). Greater than 50\% of the myofibers, predominately of type 1 , contained variably sized inclusions (Fig. 1a-d) and blue-rimmed (H\&E) or red-rimmed (modified Gomori trichrome stain) vacuoles (Fig. 1c, d). Inclusions were positive with the Congo-red (Fig. 1b, e) and crystal violet (not shown) stains, and were labeled with monoclonal antibodies against amyloid precursor protein (Fig. 1f) and amyloid beta (Fig. 1g). Accumulation of proteasomal subunits was identified with an antibody against proteosome 20S (Fig. 1h) [19, 20]. Similar histochemical changes were observed in the triceps muscle but to a lesser degree, while the cranial tibial muscle was minimally affected (not shown). Pathologic changes in the peroneal nerve biopsy were minimal (not shown) and included small numbers of fibers with myelin splitting and ballooning, which may be an age-related change [28, 29].

Multifocal areas of mild mononuclear cell infiltrations were observed in the proximal limb muscles. Immunophenotyping was performed on frozen vastus lateralis muscle biopsy sections to determine infiltrating cell lineages using established monoclonal antibodies to canine lymphocyte antigens [39]. Infiltrating cells had an endomysial distribution with invasion of non-necrotic and necrotic muscle fibers (Fig. 2a). Cellular infiltrations included CD4+ (Fig. 2b) and CD8+ (Fig. 2c) T lymphocytes, and rare $\mathrm{CD} 21+\mathrm{B}$ cells (Fig. 2d). Rare CD11C+ macrophage/dendritic cells were also observed (not shown). MHC class I, present only on capillary endothelial cells in normal muscle, was evident on infiltrating cells with increased expression on the muscle sarcolemma (Fig. 2e). Occasional MHC class II positive cells were also observed (Fig. 2f).
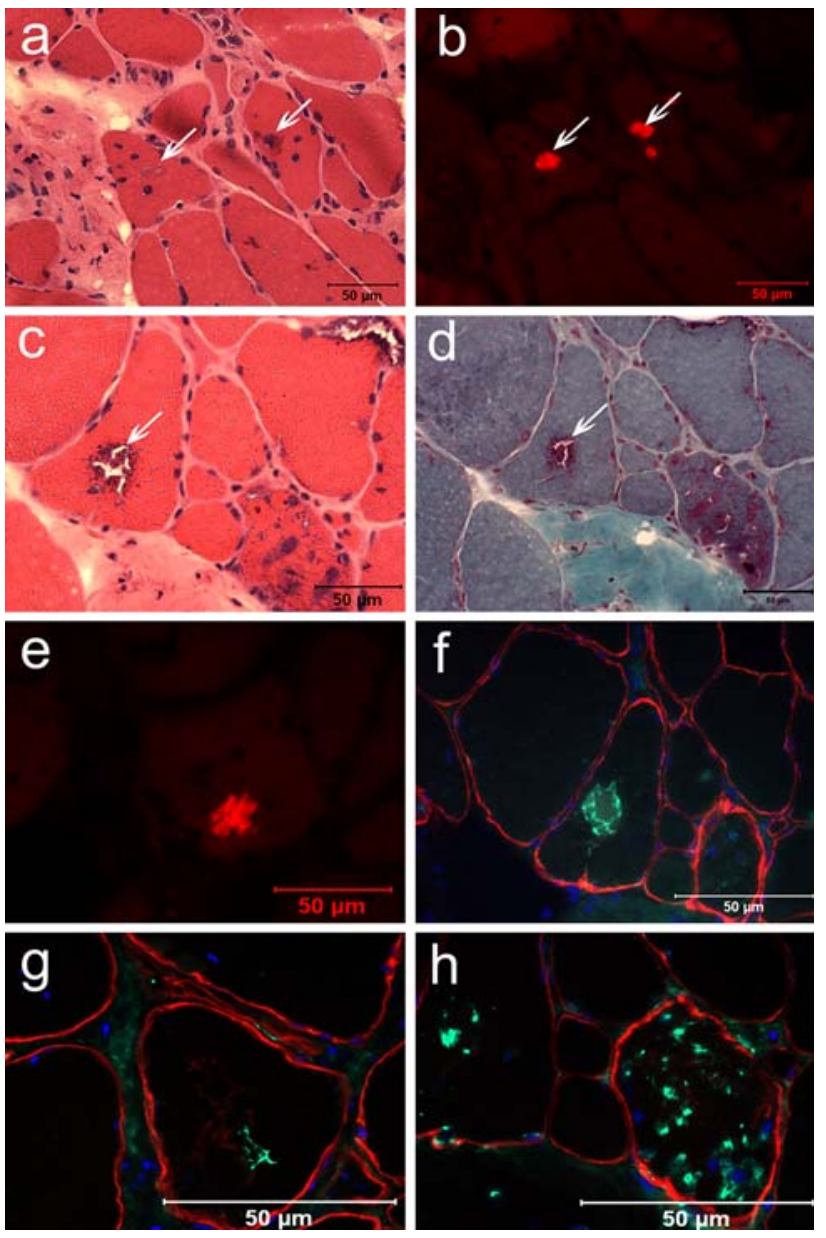

Fig. 1 Fresh frozen biopsy sections $(8 \mu \mathrm{m})$ from the vastus lateralis muscle were evaluated histologically (a, c, d), for Congo-red localization (b, e) and by immunohistochemistry (f-h). Excessive variability in myofiber size and shape, endomysial fibrosis and inclusions (arrows) were evident by light microscopy (a, H\&E). Inclusions were Congo-red positive by immunofluorescence using rhodamine optics (b, arrows). Prominent vacuoles were blue rimmed with the H\&E stain (c), red-rimmed with the modified Gomori trichrome stain (d), and contained congo-red positive material (e). Vacuoles stained positively with an antibody against amyloid precursor protein (f) and with an antibody against amyloid beta (g). Accumulation of proteasomal subunits were highlighted with an antibody against proteosome $20 \mathrm{~S}(\mathbf{h})$

Ultrastructural studies revealed membrane and nonmembrane bound subsarcolemmal inclusions that were packed with randomly dispersed filaments (Fig. 3). Subsarcolemmal filaments were oriented in different directions and measured $12-17 \mathrm{~nm}$ in diameter (Fig. 3a, inset). It is possible that the membrane bound inclusion in Fig. 3a is actually a nucleus, but a clear inner nuclear membrane was not obvious. Filaments were often surrounded by glycogen granules, irregular myeloid structures, disorganized myofibrils, degenerating mitochondria, and vacuoles. At higher power, degenerating mitochondria (Fig. 3b) coalesced into larger homogenous structures (Fig. 3c). 

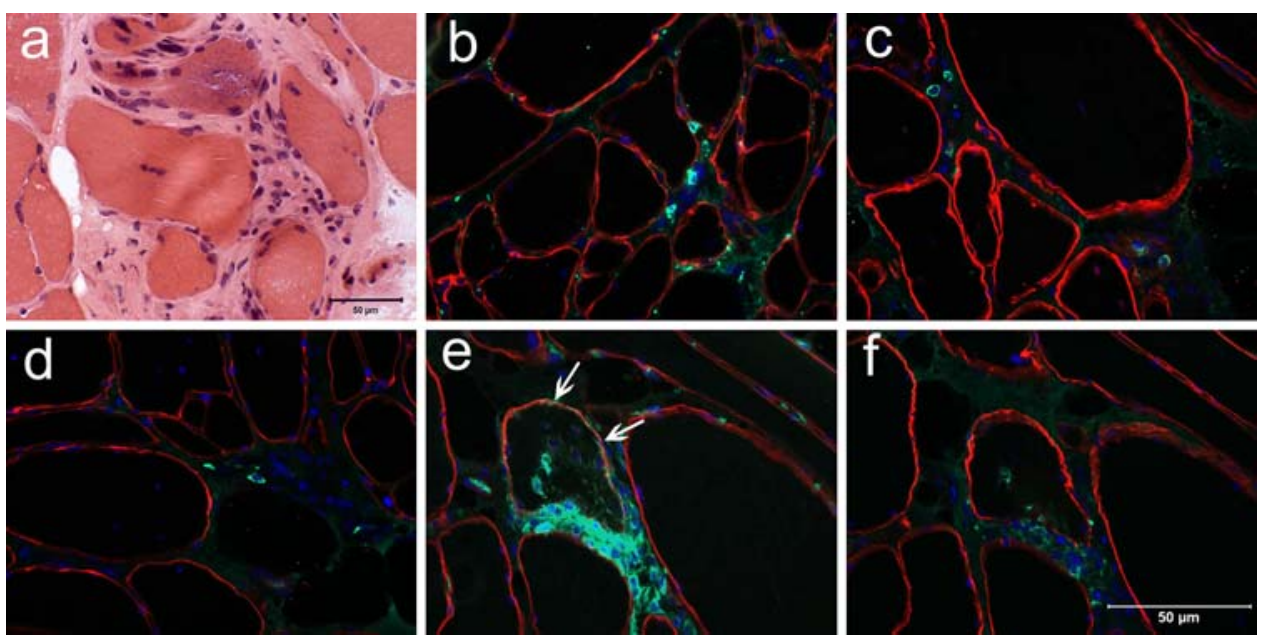

Fig. 2 Fresh frozen sections $(8 \mu \mathrm{m})$ from the vastus lateralis muscle were evaluated histologically (a) and by immunofluorescence for identification of infiltrating cells (b-d). Mononuclear cell infiltrations had an endomysial distribution (a). Monoclonal antibodies against canine leukocyte antigens (b-d), and for MHC I (e) and II (f) were used. CD4+ (b) and CD8+ (c) $\mathrm{T}$ cells were predominant with rare $\mathrm{CD} 21+(\mathbf{d})$ cells and $\mathrm{CD} 11 \mathrm{c}+$ macrophage/dendritic cells (not

\section{Discussion}

Although sIBM is the inflammatory myopathy most frequently recognized in humans over the age of 50 years and the most important muscle disease associated with aging, reports of sIBM in dogs do not exist, even though inflammatory myopathies are relatively common in this species. The present report provides convincing histologic, immunohistochemical and ultrastructural evidence that a vacuolar myopathy with many similarities to sIBM occurs in dogs.

While it is difficult to extrapolate clinical features in humans to dogs, many of the criteria for a diagnosis of sIBM in humans were present in this case. The dog had a chronic history of progressive muscle weakness and wasting that primarily affected the proximal limb muscles. Similarly, pathologic changes were more marked in proximal than distal muscles. However, on EMG examination, spontaneous activity was most pronounced in distal muscles of the thoracic limb and interosseus muscles of both the thoracic and pelvic limbs. This apparent difference may be the result of sampling error, whereby EMG changes in the larger proximal muscles were more focal in distribution, and thus more difficult to appreciate. Alternatively, proximal muscles may have been closer to end-stage. Never the less, these findings are provocative given the reports describing atrophy and weakness of the forearm musculature in association with sIBM in people [2].

Quantitative EMG (qEMG), to determine whether the EMG findings were myopathic or neuropathic in nature, is not possible in dogs due to the need for volitional activity. Human qEMG reports in SIBM are conflicting, with some shown). MHC I was evident on infiltrating cells and on the muscle sarcolemma (e, arrow to sarcolemmal localization). Occasional MHC II positive cells were also observed (f). The muscle sarcolemma was identified by an antibody against $\alpha$-sarcoglycan (red), nuclei were localized by DAPI (blue) and infiltrating cells were identified by fluorescein conjugated secondary antibodies (green). Bar in $F=50 \mu \mathrm{m}$ for all immunofluorescence figures

cases appearing myopathic, several labeled as neuropathic and others having mixed results $[2,12,26,30]$. In this case, peroneal and ulnar MNCV examination revealed changes suggestive of a mild motor neuropathy. As is the case in humans, whether these changes are age-related or a feature of sIBM in dogs is unclear. Similarly, the SNCV findings were of interest. Of the three SNCV studies performed, only the ulnar sensory nerve action potential was dispersed and decreased in amplitude. Dabby [12] describes a subset of 9 cases out of a group of 70 sIBM patients that were originally diagnosed with motor neuron disease based on clinical presentations and electrodiagnostic findings. In all nine, both motor and sensory conduction velocities were normal, but two had reduced CMAP.

As has been reported in a proportion of human SIBM patients, serum CK activity was normal [10]. Muscle biopsy features for definite sIBM in humans include the presence of congophilic deposits within muscle fibers, fibers harboring vacuoles rimmed by membranous material (rimmed vacuoles), and endomysial inflammatory exudates with or without invasion of necrotic or non-necrotic fibers. Perivascular or perimysial inflammation may or may not be present $[10,16]$. In the present case, blue-rimmed vacuoles were apparent in greater than $50 \%$ of the muscle fibers that also contained abnormal protein accumulations, including $\beta$-amyloid, and increased proteasomal accumulations (Fig. 1). Further, immunophenotyping of cellular infiltrations demonstrated CD8+ T-cells with increased expression of MHC-I (Fig. 2). Ultrastructural studies confirmed the presence of randomly dispersed filamentous inclusions, disorganized myofibrils and accumulation of degenerating organelles (Fig. 3). 


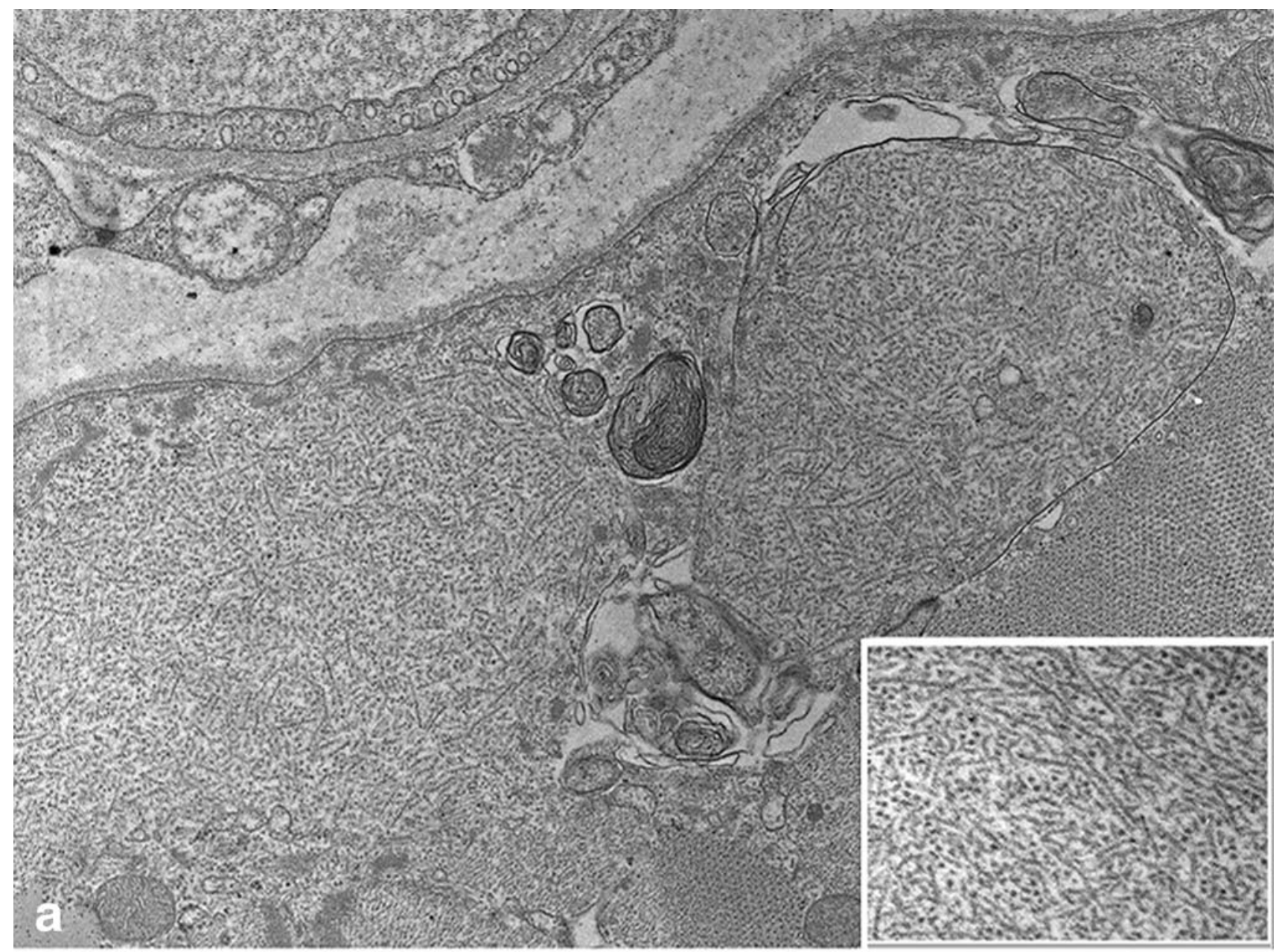

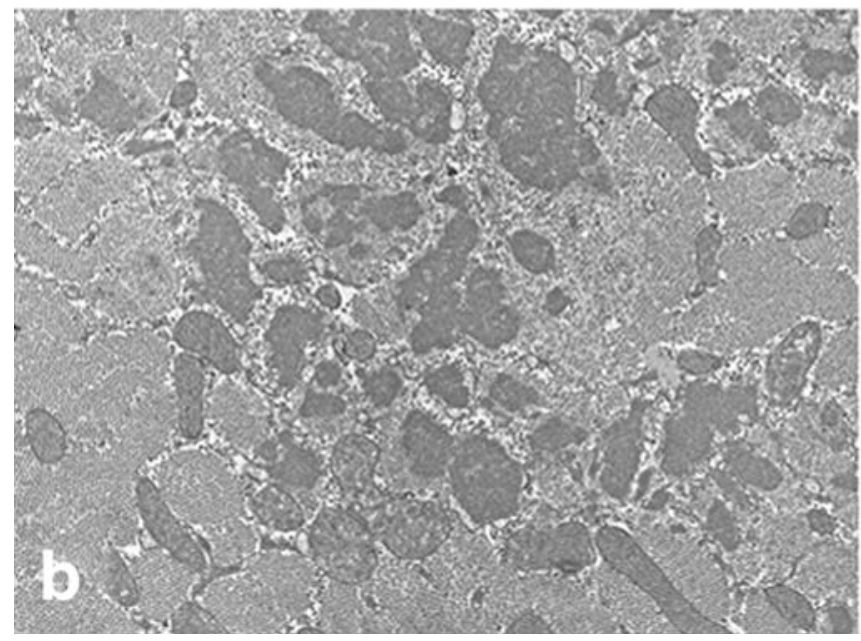

Fig. 3 Inclusions from the vastus lateralis muscle were evaluated ultrastructurally. Both membrane and non-membrane bound inclusions were evident (a) that were packed with randomly dispersed filaments. Subsarcolemmal filaments were oriented in different

The mechanism of degenerative changes occurring in muscle fibers in sIBM remains poorly understood. Pathologically, sIBM is characterized by a unique combination of changes comprising a predominantly T-cell inflammatory

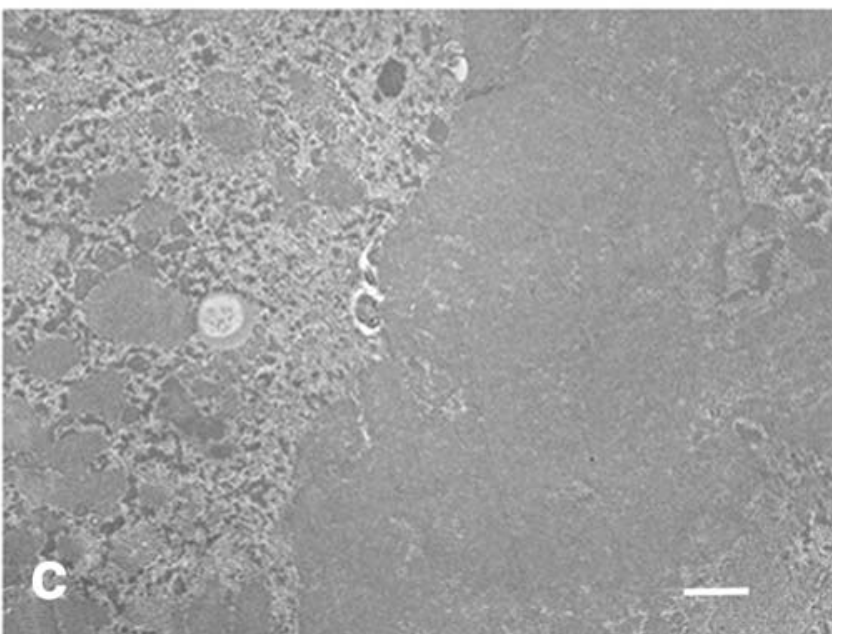

directions (a, inset) and measured $12-17 \mathrm{~nm}$ in diameter. Accumulations of degenerating mitochondria (b) were evident at high power that coalesced into larger homogenous structures (c). Bar $0.47 \mu \mathrm{m}$ for a, $0.27 \mu \mathrm{m}$ for inset, $1.2 \mu \mathrm{m}$ for $\mathbf{b}$ and $1.1 \mu \mathrm{m}$ for $\mathbf{c}$

infiltrate, muscle fibers expressing MHC-1, and congophilic inclusions and rimmed vacuoles containing $\beta$-amyloid and a variety of other proteins. In addition, muscle fibers can show loss of cytochrome $\mathrm{c}$ oxidase activity, a 
mitochondrial-specific enzyme. Thus, it is still debated whether sIBM is primarily a T-cell mediated inflammatory myopathy or a myodegenerative disorder with abnormal protein aggregation, inclusion body formation and a secondary inflammatory response in muscle. It is clear, however, that intracellular accumulation of amyloid- $\beta$ precursor protein, amyloid- $\beta$, and amyloid- $\beta$ oligomers in the cellular milieu of an aging muscle is a key pathogenic factor $[4,5]$.

In summary, much useful information can be gained from animal models. Rodents provide important models for studying molecular pathogenesis and the effects of gene manipulations and cell transplantation. On the other hand, larger animal homologs of human myopathies, such as the dog, may provide more clinically relevant models. Currently available models of sIBM have not accurately replicated the clinical and pathological aspects of human sIBM. In fact, one recent literature review of sIBM [22] suggests that most of the available animal models may be flawed and that their use could actually lead to clinical studies in humans utilizing potentially harmful drugs. In the present case, many of the clinical and pathological aspects of human sIBM were fulfilled. While only one case of a sIBM-like myopathy has been confirmed in an aged dog to date, it is possible that muscle wasting and weakness in aged dogs is mistaken as arthritis or just a result of aging, and appropriate diagnostic testing not performed. Further study of naturally occurring canine sIBM-like myopathies may provide valuable information on the mechanism of degenerative and inflammatory changes in aging IBM muscle. Factors that result in sIBM in people may be similar to those resulting in sIBM-like myopathies of older dogs. The identification of sIBM-like changes in our case is only a first step. Based on this report, in-depth studies of normal aging changes in canine muscle and in dogs with chronic and progressive degenerative myopathies are clearly necessary.

Acknowledgments The authors thank the Muscular Dystrophy Association and the Jain Foundation for funding studies on canine myopathies (GDS), Norma Huff for excellent technical support, and Dr. Eva Engvall for valuable comments on the manuscript.

Open Access This article is distributed under the terms of the Creative Commons Attribution Noncommercial License which permits any noncommercial use, distribution, and reproduction in any medium, provided the original author(s) and source are credited.

\section{References}

1. Allgoewer I, Blair M, Basher T et al (2000) Extraocular muscle myositis and restrictive strabismus in 10 dogs. Vet Ophthalmol $3: 21-26$
2. Amato AA, Dumitru D (2001) Acquired myopathies. In: Dumitru D, Amato AA, Zwarts MJ (eds) Electrodiagnostic medicine, 2nd edn. Hanley and Belfus, Philadelphia, pp 1371-1432

3. Askanas V, Engel WK (1998) Newest approaches to diagnosis and pathogenesis of sporadic inclusion-body myositis and hereditary inclusion-body myopathies, including molecular-pathologic similarities to Alzheimer disease. In: Askanas V, Serratrice G, Engel WK (eds) Inclusion-body myositis and myopathies. Cambridge University, Cambridge, pp 3-78

4. Askanas V, Engel WK (2007) Inclusion-body myositis, a multifactorial muscle disease associated with aging: current concepts of pathogenesis. Curr Opin Rheumatol 19:550-559

5. Askanas V, Engel WK (2008) Inclusion-body myositis: musclefiber molecular pathology and possible pathogenic significance of its similarity to Alzheimer's and Parkinson's disease brains. Acta Neuropathol 116:595-883

6. Askanas V, Engel WK, Alvarez R (1993) Enhanced detection of Congo-red-positive amyloid deposits in muscle fibers of inclusion body myositis and brain of Alzheimer's disease using fluorescence technique. Neurology 43:1265-1267

7. Bassez G, Authier FJ, Lechapt-Zalcman E et al (2003) Inflammatory myopathy with abundant macrophages (IMAM): a condition sharing similarities with cytophagic histiocytic paniculitis and distinct from macrophagic myofasciitis. J Neuropathol Exp Neurol 62:464-474

8. Buoro IBJ, Kanui TI, Atwell RB, Njenga KM, Gathumbi PK (1990) Polymyositis associated with Ehrlichia canis infection in 2 dogs. J Small Anim Pract 31:624-627

9. Carpenter JL, Schmidt GM, Moore FM, Albert DM, Abrams KI, Elner VM (1989) Canine bilateral extraocular polymyositis. Vet Pathol 26:510-512

10. Chahin N, Engel AG (2008) Correlation of muscle biopsy, clinical course, and outcome in PM and sporadic IBM. Neurology 70:418-424

11. Gherardi RK, Coquet M, Cherin P et al (1998) Macrophagic myofasciitis: an emerging entity. Groupe d'Etudes et Recherche sur les Maladies Musculaires Acquises et Dysimmunitaires (GERFMMAD) de l'Association Francaise contre les Myopathies (AFM). Lancet 352:347-352

12. Dabby R, Lange DJ, Trojaborg W et al (2001) Inclusion body myositis mimicking motor neuron disease. Arch Neurol 58:12531256

13. Dalakas MC, Hohlfeld R (2003) Polymyositis and dermatomyositis. Lancet 362:971-982

14. Dubey JP (1996) A review of Neospora caninum and neosporosis. Vet Parasitol 67:1-59

15. Dubowitz V, Sewry CA (2007). Histological and histochemical stains and reactions. In: Muscle biopsy: a practical approach, 3rd edn. Saunders Elsevier, St. Louis, pp 21-39

16. Engel AG, Hohlfeld R (2004) The polymyositis and dermatomyositis syndromes. In: Engel AG, Franzini-Armstrong C (eds) Myology, 3rd edn. McGraw-Hill, New York, pp 1321-1366

17. Engel WK, Askanas V (2006) Inclusion-body myositis. Clinical, diagnostic, and pathologic aspects. Neurology 66:S20S29

18. Evans J, Levesque D, Shelton GD (2004) Canine inflammatory myopathies: a clinicopathologic review of 200 cases. J Vet Intern Med 18:679-691

19. Ferrer I, Martin B, Castano JG, Lucas JJ, Moreno D, Olive M (2004) Proteasomal expression, induction of immunoproteasome subunits, and local MHC Class I presentation in myofibrillar myopathy and inclusion body myositis. J Neuropath Exp Neurol 63:484-494

20. Fratta P, Engel WK, McFerrin J, Davies KJ, Lin SW, Askansas V (2005) Proteasome inhibition and aggresome formation in sporadic inclusion-body myositis and in amyloid-beta precursor 
protein-overexpressing cultured human muscle fibers. Am J Pathol 167:517-526

21. Gobel F (1952) Observations in Chagas' disease in dogs. Am J Trop Med Hyg 1:189-204

22. Greenberg SA (2009) Inclusion body myositis: review of recent literature. Curr Neurol Neurosci Rep 9:83-89

23. Hargis AM, Haupt KH, Hegreberg GA, Prieur DJ, Moore MP (1984) Familial canine dermatomyositis: initial characterization of the cutaneous and muscular lesions. Am J Pathol 116:234244

24. Hargis AM, Prieur DJ, Haupt KH, Collier JJ, Evermann JF, Ladiges WG (1986) Postmortem findings in four litters of dogs with familial canine dermatomyositis. Am J Pathol 123:480-496

25. Haupt KH, Prieur DJ, Moore MP et al (1985) Familial canine dermatomyositis: clinical, electrodiagnostic, and genetic studies. Am J Vet Res 46:1861-1869

26. Hermanns B, Molnar M, Schroder JM (2000) Peripheral neuropathy associated with hereditary and sporadic inclusion body myositis: confirmation by electron microscopy and morphometry. J Neurol Sci 179:92-102

27. Kornegay JN, Gorgacz E, Dawe DL, Bowen JM, White NA, DeBuysscher EV (1980) Polymyositis in dogs. J Am Vet Med Assoc 176:431-438

28. Krinke G, Suter J, Hess R (1981) Radicular myelinopathy in aging rats. Vet Pathol 18:335-341

29. Krinke G (1983) Spinal radiculoneuropathy in aging rats: demyelination secondary to neuronal dwindling? Acta Neuropathol 59:63-69

30. Luciano CA, Dalakas MC (1997) Inclusion body myositis: no evidence for a neurogenic component. Neurology 48:29-33

31. Macintire DK, Vincent-Johnson NA, Kane CW, Lindsay DS, Blagbum BL, Dillon AR (2001) Treatment of dogs with Hepatozoon americanum: 53 cases (1989-1998). J Am Vet Med Assoc 218:77-82

32. Mikol J, Engel AG (2004) Inclusion body myositis. In: Engel AG, Franzini-Armstrong (eds) Myology, 3rd edn. McGraw-Hill, New York, pp 1367-1388
33. Mizisin AP, Nelson RW, Sturges BK et al (2007) Comparable myelinated nerve pathology in feline and human diabetes mellitus. Acta Neuropathol 113:431-442

34. Needham M, Corbett A, Day T, Christiansen F, Fabian V, Mastaglia FL (2008) Prevalance of sporadic inclusion body myositis and factors contributing to delayed diagnosis. J Clin Neurosci 15:1350-1353

35. Needham M, Mastaglia FL (2008) Sporadic inclusion body myositis: a continuing puzzle. Neuromuscul Disord 18:6-16

36. Neiderhauser UB, Holliday TA, Hyde DM, McQuarrie AD, Fisher LD (1990) Correlation of sensory electroneurographic recordings and myelinated fiber diameters of the superficial peroneal nerve of dogs. Am J Vet Res 51:1587-1595

37. Orvis JA, Cardinet GH III (1981) Canine muscle fiber types and susceptibility of masticatory muscles to myositis. Muscle Nerve 4:354-359

38. Paciello O, Oliva G, Gradoni L et al (2009) Canine inflammatory myopathy associated with Leishmania Infantum infection. Neuromuscul Disord 19:124-130

39. Pumarola M, Moore PF, Shelton GD (2004) Canine inflammatory myopathy: analysis of cellular infiltrates. Muscle Nerve 29:782789

40. Redding RW, Ingram JT, Colter SB (1982) Sensory nerve conduction velocity of cutaneous afferents of the radial, ulnar, peroneal, and tibial nerves of the dog: reference values. Am J Vet Res 43:517-521

41. Shelton GD (2007) From dog to man: The broad spectrum of inflammatory myopathies. Neuromuscul Disord 17:663-670

42. Shelton GD, Cardinet GH III, Bandman E (1987) Canine masticatory muscle disorders: a study of 29 cases. Muscle Nerve 10:753-766

43. Tuler SM, Bowen JM (1990) Measurement of conduction velocity of the peroneal nerve based on recordings from extensor digitorum brevis muscle. J Am Anim Hosp Assoc 26:164-168

44. Walker TL, Redding RW, Braund KG (1979) Motor nerve conduction velocity and latency in the dog. Am J Vet Res 40:14331439 